\title{
Influence of fly ash particles on dry sliding wear behaviour of AA6061 aluminium alloy
}

\author{
J. David Raja Selvam ${ }^{*}$, D. S. Robinson Smart ${ }^{2}$, I. Dinaharan ${ }^{3}$ \\ ${ }^{1}$ Centre for Research in Metallurgy (CRM), School of Mechanical Sciences, Karunya University, \\ Coimbatore 641114, Tamil Nadu, India \\ ${ }^{2}$ School of Mechanical Sciences, Karunya University, Coimbatore 641114, Tamil Nadu, India \\ ${ }^{3}$ Department of Mechanical Engineering Science, University of Johannesburg, Auckland Park Kingsway Campus, \\ Johannesburg 2006, South Africa
}

Received 11 July 2014, received in revised form 12 March 2015, accepted 27 June 2015

\begin{abstract}
In the present study AA6061 aluminium alloy composites containing 0, 4, 8 and 12 wt.\% of fly ash particles have been fabricated by the compocasting process. The dry sliding wear behaviour of unreinforced alloy and composites are studied using pin-on-disc machine. The dry sliding wear test was conducted under a load of 4.9, 9.8, 14.7, 19.6, and $24.5 \mathrm{~N}$, sliding velocity of $1.57 \mathrm{~m} \mathrm{~s}^{-1}$, sliding distance of $4000 \mathrm{~m}$ and a track radius of $100 \mathrm{~mm}$ at an ambient temperature respectively for all the tests. Results indicate that the dry sliding wear resistance of Al-fly ash composite increases with an increase of fly ash content. The load bearing capacity of the AA6061 alloy during dry sliding wear has increased in the presence of fly ash particles. Composites exhibit better wear resistance compared to unreinforced alloy up to a load of $24.5 \mathrm{~N}$. Study of the wear surfaces and debris of both alloy and composites using the scanning electron microscope suggests that at high loads $(>4.9 \mathrm{~N})$, where fly ash particles act as load bearing constituents, the wear resistance of AA6061 Al alloy reinforced with a size range $(2-3 \mu \mathrm{m})$ fly ash particles.

Key words: aluminium matrix composite (AMC), wear, fly ash
\end{abstract}

\section{Introduction}

In general, the incorporation of hard ceramic particles into the aluminium matrix improves the wear resistance of aluminium alloys. Due to this aluminium matrix composites (AMCs) are progressively replacing aluminium alloys in many applications where components slide against each other. The sliding action results in wear of components which is influenced by several factors such as the speed, the running hour and the load acting on the component [1-3]. It is essential to calculate the effect of those factors on the wear rate of composites. The wear rate of traditional aluminium alloys reinforced with $\mathrm{SiC}$ and $\mathrm{Al}_{2} \mathrm{O}_{3}$ particles was studied extensively by several researchers [4-7]. However, the sliding wear behaviour of fly ash reinforced composites has not been explored in sufficient depth.
Fly ash, an industrial waste either solid (precipitate) or hollow (cenosphere) can be added to aluminium to improve the mechanical properties of the composites. Fly ash can be successfully incorporated in aluminium to make complex shapes of selected industrial components like differential covers, intake manifolds, brake drums and outdoor equipment castings [8]. Infiltration of fly ash cenospheres in pure $\mathrm{Al}$ matrix decreases its coefficient of thermal expansion that is dependent on infiltration pressure, longer infiltration time, and temperature [9]. Aluminium fly ash composites can be synthesised through the liquid metal stir casting, compocasting (semi-solid processing), modified compocasting and squeeze casting technique. Squeeze casting route produces better well dispersed and relatively agglomerate and porosity free fly ash particle composites [10-14].

Damping capacity of the as-received Al showed a

\footnotetext{
*Corresponding author: tel.: +91-9487846895; fax: +91-0422-2575020; e-mail address: jdavidselvam@gmail.com
} 
significant increase by the accession of the fly ash particle when evaluated in the bending vibration mode [15-17]. The stiffness, tensile force, compression force, impact force and the damping effect increase by the addition fly ash particles to the aluminium alloy AA6061, whereas density decreases by the addition of fly ash particles. Resistance to dry wear and slurry erosive wear also increased with increase in fly ash content [18-21]. Brake lining friction composites, using fly ash with ingredients such as phenolic resin, aramid pulp, glass fibre, potassium titanate, graphite, aluminium fibre and copper powder exhibit consistently better coefficients of friction and low wear rates [22-24].

Abrasive wear resistance of alloy containing fly ash is superior to that of the aluminium base alloy [1821]. The primary wear mechanism of aluminium alloy AA6061 was micro cutting, but the wear mechanism of the composite was micro cutting, abrasion, and delamination caused by crack propagation below the rubbing surface due to the addition of hard fly ash and silicon particles with the matrix [22-27]. The present work describes the influence of fly ash particles on the dry sliding wear behaviour of AA6061 alloy and AA6061/fly ash composite fabricated by the composting process at an ambient room temperature.

\section{Experimental procedure}

AA6061/fly ash with different weight percentage composites were prepared by the compocasting technique. The cast composites were fabricated with various weight of percentage of fly ash of $0,4,8$ and 12. The detailed process parameter for the fabrication of the AMCs is available in existing literature. Specimens were prepared from the castings to carry out microstructural characterisation. The specimens were polished using standard metallographic technique and etched with Keller's reagent. The etched specimens were observed using a scanning electron microscope (JEOL-JSM-6390). X-ray diffraction patterns (XRD) were recorded using Panalytical X-ray diffractometer.

The dry sliding wear tests were conducted on a pin-on-disc wear testing machine (TR-20, DUCOM, Bangalore, India) as shown in Fig. 1 according to the ASTM G99-04 Standard. The square pins of dimension $6 \mathrm{~mm} \times 6 \mathrm{~mm} \times 30 \mathrm{~mm}$ were obtained from the alloy and composite was used as wear test sample. The one end of the sample was slide on the hardened chromium steel (Rc64). The tests were carried out at different loads $(4.9,9.8,14.7,19.6$, and $24.5 \mathrm{~N})$ respectively at a sliding speed of $1.57 \mathrm{~m} \mathrm{~s}^{-1}$, sliding distance of $4000 \mathrm{~m}$ and tests were carried out at ambient temperature without any lubrication [21, 22]. These experimental conditions were selected from several trials conducted. At least three trials were carried out for each set of parameter to get a representative data. A computer-aided data acquisition system was used to monitor the loss of height. The volumetric loss was computed by multiplying the cross section of the

Table 1. Wear test plan

\begin{tabular}{|c|c|c|c|c|}
\hline \multirow{2}{*}{ Trial run } & \multicolumn{4}{|c|}{ Sliding wear parameters } \\
\hline & $\begin{array}{l}\text { Sliding velocity } \\
\qquad\left(\mathrm{m} \mathrm{s}^{-1}\right)\end{array}$ & $\begin{array}{l}\text { Sliding distance } \\
(\mathrm{mm})\end{array}$ & $\begin{array}{l}\text { Normal force } \\
(\mathrm{N})\end{array}$ & $\begin{array}{l}\text { Composition } \\
\text { (wt.\% of FA) }\end{array}$ \\
\hline T01 & 1.57 & 4000 & 5 & 0 \\
\hline T02 & 1.57 & 4000 & 5 & 4 \\
\hline T03 & 1.57 & 4000 & 5 & 8 \\
\hline T04 & 1.57 & 4000 & 5 & 12 \\
\hline T05 & 1.57 & 4000 & 10 & 0 \\
\hline T06 & 1.57 & 4000 & 10 & 4 \\
\hline T07 & 1.57 & 4000 & 10 & 8 \\
\hline T08 & 1.57 & 4000 & 10 & 12 \\
\hline T09 & 1.57 & 4000 & 15 & 0 \\
\hline $\mathrm{T} 10$ & 1.57 & 4000 & 15 & 4 \\
\hline $\mathrm{T} 11$ & 1.57 & 4000 & 15 & 8 \\
\hline $\mathrm{T} 12$ & 1.57 & 4000 & 15 & 12 \\
\hline $\mathrm{T} 13$ & 1.57 & 4000 & 20 & 0 \\
\hline $\mathrm{T} 14$ & 1.57 & 4000 & 20 & 4 \\
\hline $\mathrm{T} 15$ & 1.57 & 4000 & 20 & 8 \\
\hline T16 & 1.57 & 4000 & 20 & 12 \\
\hline $\mathrm{T} 17$ & 1.57 & 4000 & 25 & 0 \\
\hline $\mathrm{T} 18$ & 1.57 & 4000 & 25 & 4 \\
\hline $\mathrm{T} 19$ & 1.57 & 4000 & 25 & 8 \\
\hline T20 & 1.57 & 4000 & 25 & 12 \\
\hline
\end{tabular}




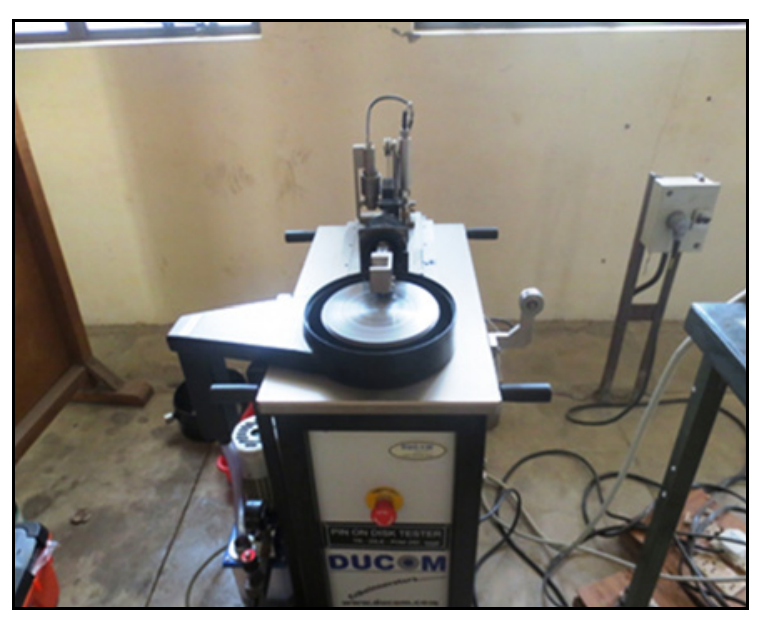

Fig. 1. Pin-on-disc experimental setup.
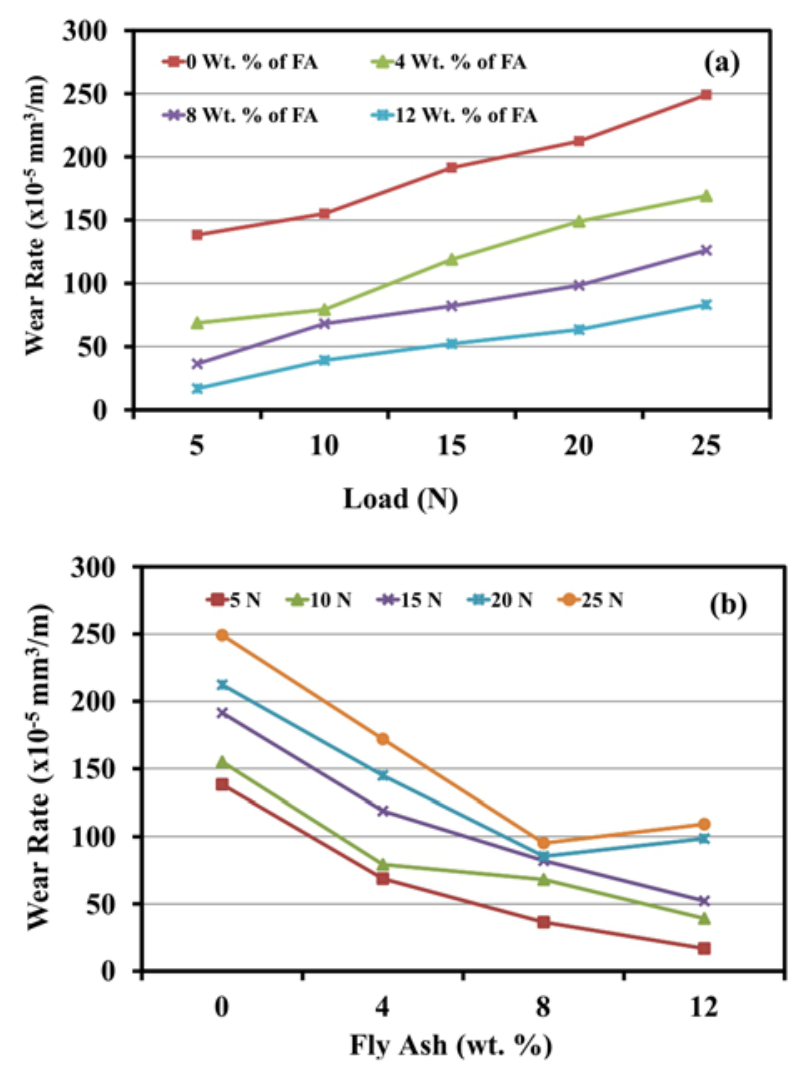

Fig. 2. Wear rate of AA 6061 alloy-based MMCs as a function of (a) normal load applied; (b) wt.\% fly ash.

test pin with its loss of height. The wear rate was calculated by splitting up with the volumetric loss with sliding distance. The experiments were carried out as shown in Table 1. Before starting each wear test, the disc surface was regularly and thoroughly cleaned with acetone before and after wear test.

\section{Results and discussion}

\subsection{Wear rate of composite as a function of reinforcement and load}

Figures 2a,b show the results of dry sliding wear behaviour of AMCs with $0,4,8$, and 12 wt.\% of fly ash content, wear rates of the base alloy and the composites are shown in Figs. 2a,b as a function of load and wt.\% of fly ash, respectively. It was observed that the wear rate decreases with increasing fly ash content. The figures show that for a constant load and sliding speed, the wear rate decreases as a function of the amount of fly ash content and the wear rate increases as the load increases. It is evident from Fig. 2a that the addition of $4 \mathrm{wt} . \%$ fly ash to the base alloy decreases the wear rate by about 1.27 times for all the loads studied. The lower wear rates in composites with a higher amount of fly ash particles can be attributed to the high peak hardness and good interfacial bond of the aluminium matrix composites.

In composites with coarse particles, the interfacial strength is high due to the large surface bonding of particles with the aluminium matrix, which avoids particle pull out and the matrix holds the particle strongly until the particles break down into small particles. This may be due to the breakage of the particles at a relatively faster rate due to the large size of the particles. Microthermal softening of matrix material may also happen at high speeds, which further reduces the bonding strength of fly ash particles with the matrix material. Nevertheless, the decrease in wear rate with an increase of fly ash particulate is not onedimensional, which may be attributed to the complex processes happening during the wear of the composites. The addition of fly ash particles improves the hardness of the matrix alloy that reduces the rate of material removal. The thermal expansion coefficient of AA6061 is $23.5 \times 10^{-6}{ }^{\circ} \mathrm{C}$ while that of fly ash is $6.6 \times$ $10^{-6}{ }^{\circ} \mathrm{C}$. This difference in thermal expansion between matrix and reinforcement tends to append high density of dislocations around fly ash particles during solidification. The interaction between fly ash particles and dislocations enhances the wear resistance.

Figures 3a,b show the wear resistance, defined as the reciprocal of wear rate, of the composites as a function of normal loads and fly ash content, respectively. Figure 3b shows that for a fixed normal load, the wear resistance increases as a function of the amount of fly ash in the composites. The AMCs with 4 wt.\% of the fraction of fly ash underwent large wear and the wear increased almost linearly with time. Base metal showed higher wear and MMC with 4 wt.\% fly ash showed lower wear. In the initial wear regime, the reinforced fly ash particles act as load carrying elements and as inhibitors against plastic deformation and adhesion of matrix material. 

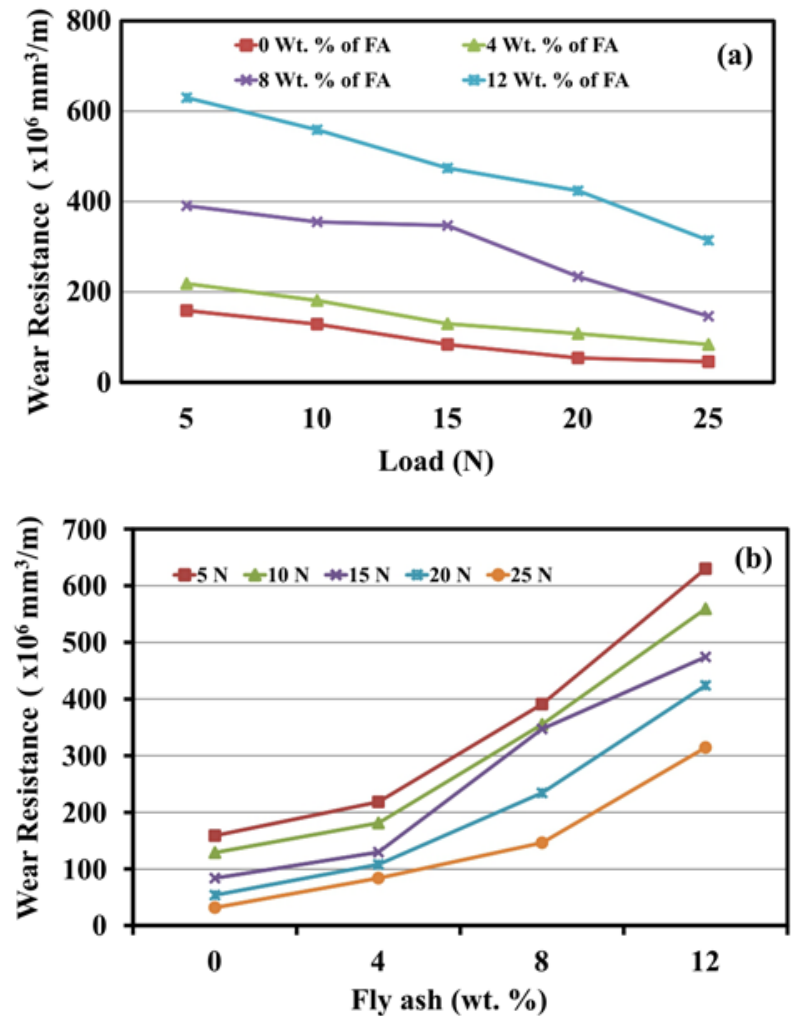

Fig. 3. Wear resistance of AA 6061 alloy-based MMCs as a function of (a) normal load applied; (b) wt.\% fly ash.

The inherent characteristic of compocasting technique, the fabrication method is the ability to offer a better interface between reinforcement and the matrix alloy. The details of the fabricated matrix with a better interface between the AA6061 alloy and fly ash particle are published in the earlier work mentioned by the authors [27]. The finer interface of the fly ash increases the load bearing capacity of the AMC which means higher stress is required initially to cracking. This brings down the wear resistance of the composite with increased content of fly ash particles. Further, the spherical shape of the particles delays cracks initiation. The interaction between fly ash particles and dislocations enhances the wear resistance.

Figures $4 a, b$ show the wear rate per unit wt.\% of fly ash at different normal loads. It is very clear from the figure that wear rate per unit wt.\% of fly ash also decreases with an increase of fly ash for any load under consideration. This parameter clearly brings out the improvement in inherent specific wear resistance of the composite with an increase in the quantity of reinforcement. It is also interesting to note from the figure that the specific wear resistance wt.\% of fly ash is almost insensitive to the load, particularly at fly ash levels 4 to 12 wt.\%, within the range of load studied $(4.98-24.9 \mathrm{~N})$. Also, it should be noted that wear rate per unit wt.\% of fly ash drastically decreases above
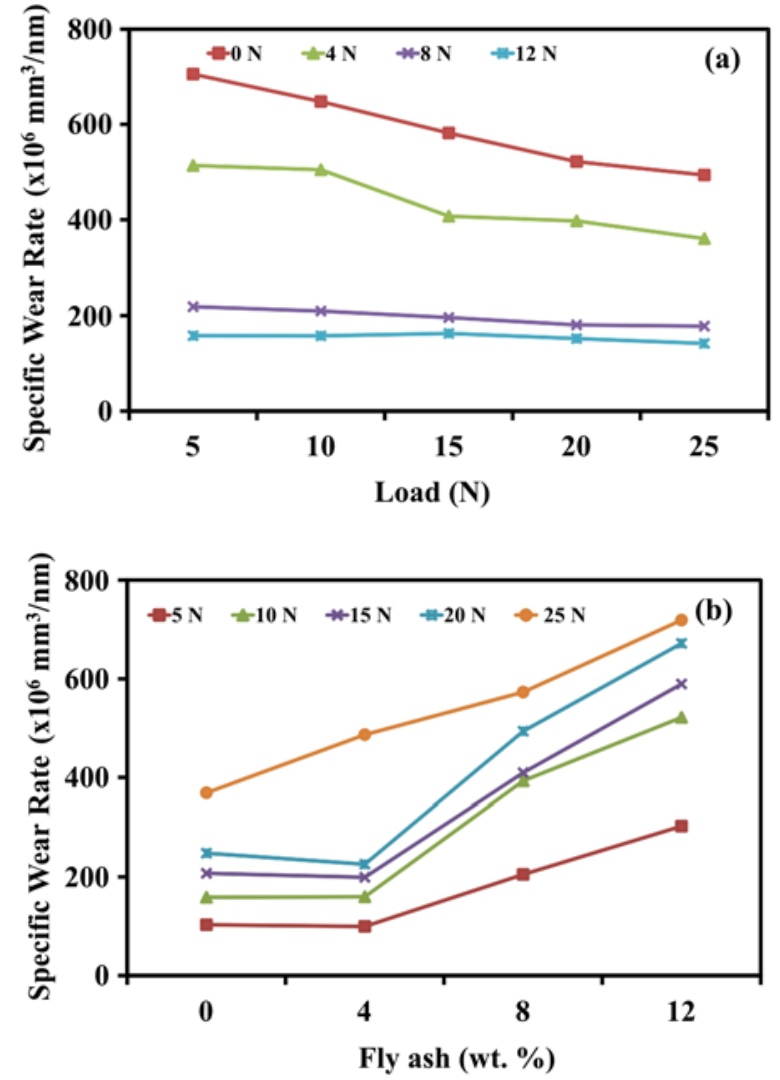

Fig. 4. Specific wear rate of AA 6061 alloy-based MMCs as a function of (a) normal load applied; (b) wt.\% fly ash.

4 wt.\% fly ash. This may be attributed to the decrease in the $\alpha$-Al cell size at higher weight fractions of fly ash particles [16]. Therefore, both the grain refining action of the fly ash particles, as well as the high stiffness of the composites, play a critical part in decreasing the wear rates. It is worth mentioning that the specific wear rate wt.\% of the reinforcement is too an important parameter that should be taken into consideration.

Figures $5 \mathrm{a}-\mathrm{d}$ show SEM images of the wear surfaces of the compocast AMC. It is observed that a combination of both adhesive and abrasive wear is observed for the MMC. Adhesive delamination is observed in Fig. 5a. Figure 5b shows the presence of gouging by hard fly ash particles in AA6061 alloy that might lead to the slightly larger volume loss as observed. The softer aluminium phase has piled up ahead of the cenosphere particle. The presence of grooves and scratches due to micro-cutting is also observed in all the wear samples that are indicating the abrasive wear. Delamination craters are observed in compocast AMC, which is referable to the adhesive pull out of debonded particles. Adhesive wear and delamination kind of phenomena are also seen in Figs. 5a,b. 

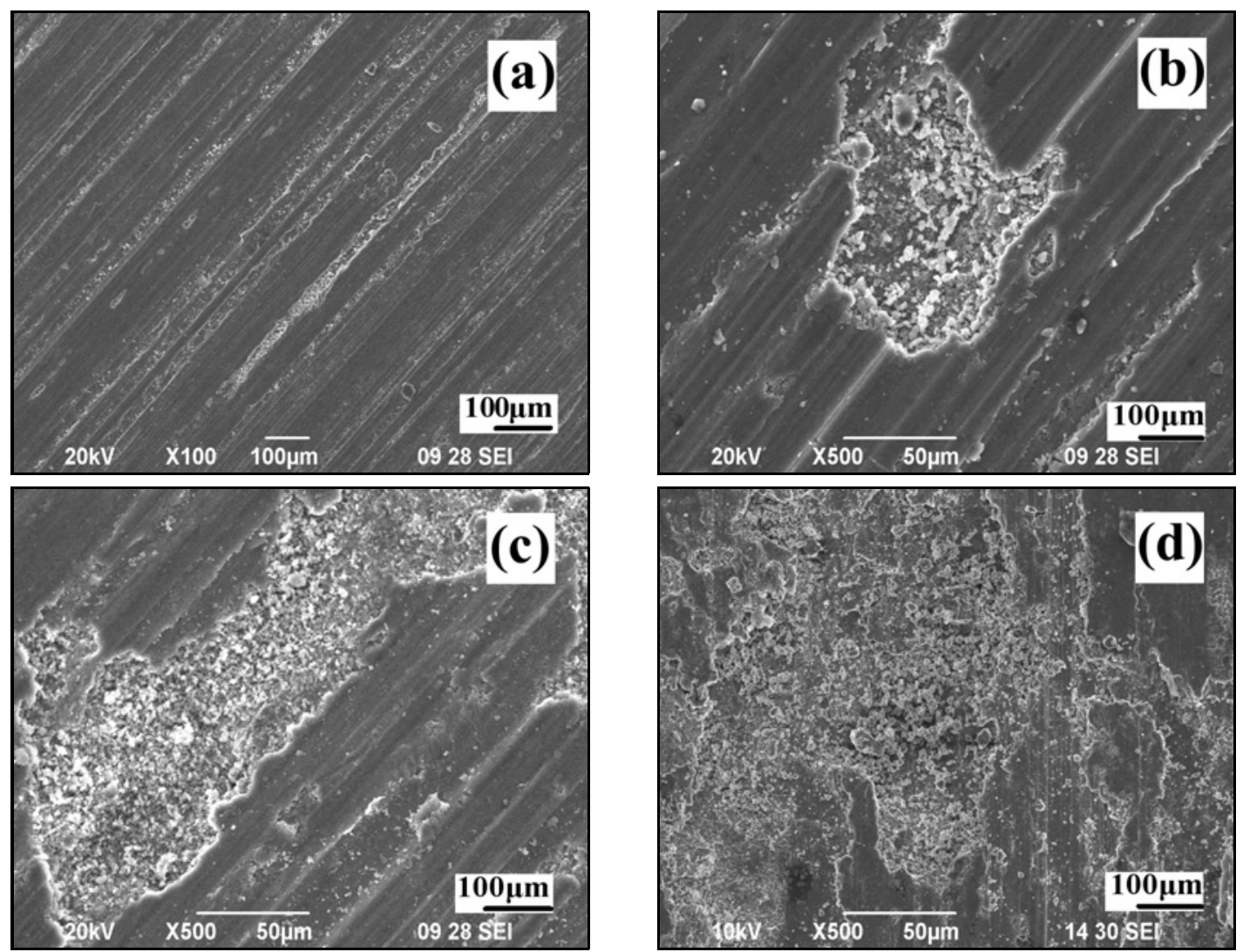

Fig. 5. SEM photomicrographs of wear surfaces of (a and b) AA 6061 alloy and (c and d ) AA 6061-12 wt.\% fly ash tested under a normal load of $24.9 \mathrm{~N}$.
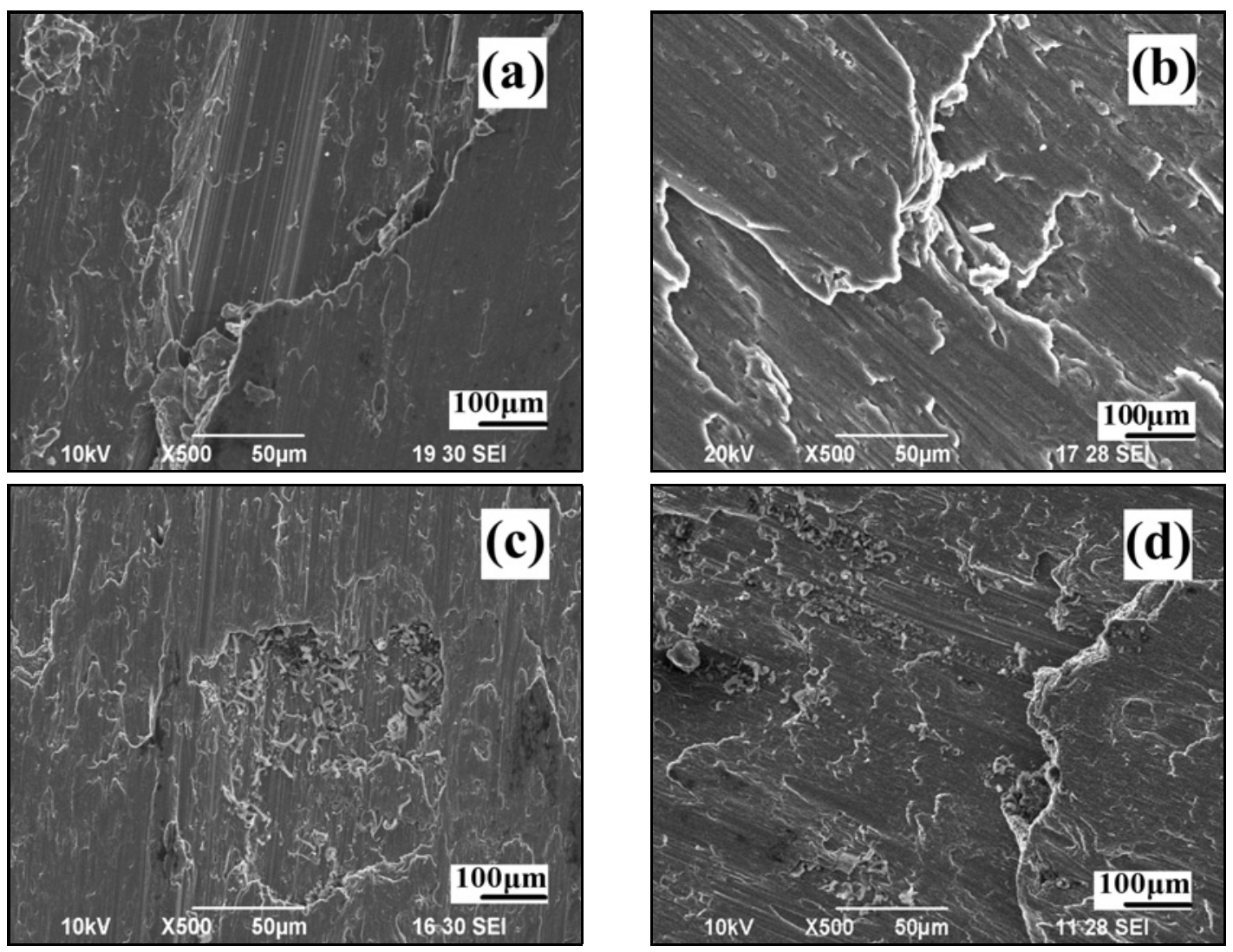

Fig. 6. SEM images of the wear surface for a-d. AMC after wear. 

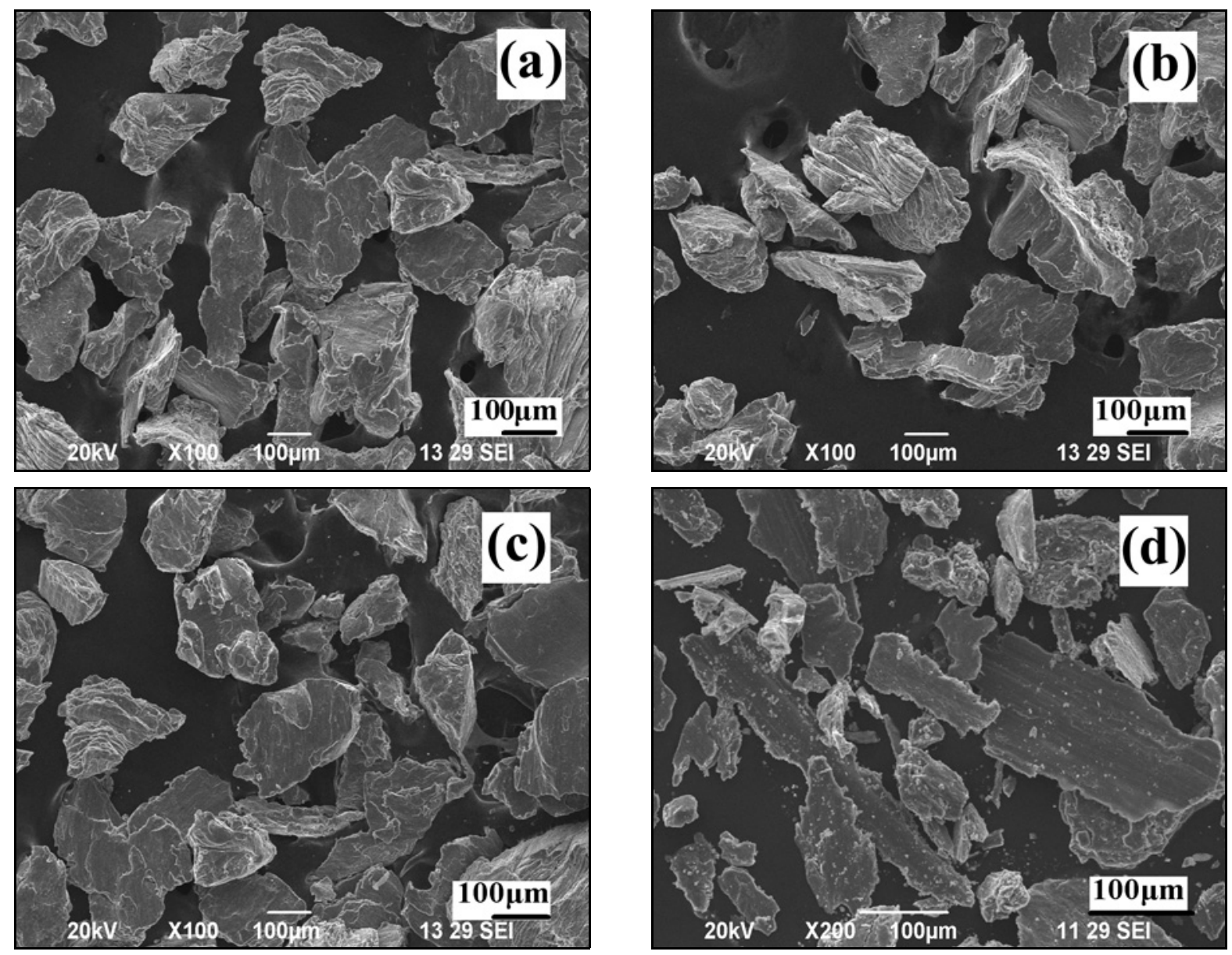

Fig. 7. SEM photomicrographs of wear debris of AA 6061 alloy reinforced with fly ash particles (a) 0 wt.\%; (b) 4 wt.\%; (c) 8 wt.\%; (d) 12 wt.\% tested under a normal load of $4.98 \mathrm{~N}$.

\subsection{Analysis of wear debris and wear surfaces}

Dry sliding wear involves the transfer of material from one surface to another during relative motion due to a process of solid-state joining or wear due to localised bonding between contacting solid surfaces. The dry sliding wear tends to material transfer between the disc and pin or loss from either surface. The SEM analysis of wear debris formed during the dry sliding wear in the room temperature provides a significant tool to understand the wear behaviour of the composites more accurately.

Scanning electron microscopy (SEM) of wear particles collected from continuous tests showed large particle agglomerates. These agglomerates consist of submicron and micron sized molecules in a diversity of configurations. Figures 6a,b are SEM micrographs of wear particle agglomerates generated during wear test. It can be understood that the grooves are deeper in the base alloy as compared to the composites tested under similar conditions $(29.4 \mathrm{~N})$ due to the absence of hard fly ash particles in the former as observed from Figs. 6a,c. Also, the wear surfaces in the steady state wear regime in the base alloy seem to be quite smooth as compared to the composites. This can also be attributed to the absence of fly ash particles that otherwise cause the micro plowing of the surface in contact during wear making the surface rough.

These were distributed evenly throughout the worn surface and eventually broke off to become debris. Interestingly, as the fly ash content increases, Figs. 6b,d, the surface charging occurrence is enhanced with the increase in weight percentage of fly ash particles suggesting that the worn out surface is easily oxidised during surface charging. Also, the frictional heating during the wear enhances the oxidation of the finer wear debris more easily than the coarser ones.

It is worth noting that the size of the wear debris (for each weight percentage) generated depends on the normal load applied and the weight percentage of fly ash. At lower loads $(5 \mathrm{~N})$, the particle size of the debris appears to be independent of the amount of fly ash as shown in Figs. 6a-d. However, at higher load $(24.9 \mathrm{~N})$ the composite with $12 \mathrm{wt} . \%$ fly ash clearly defined to form smaller particles in the debris as shown in Figs. $7 \mathrm{a}-\mathrm{d}$. The bearing of both crystals of equal length as well as eccentric debris can be picked up from the micrographs. This could perhaps be due to 

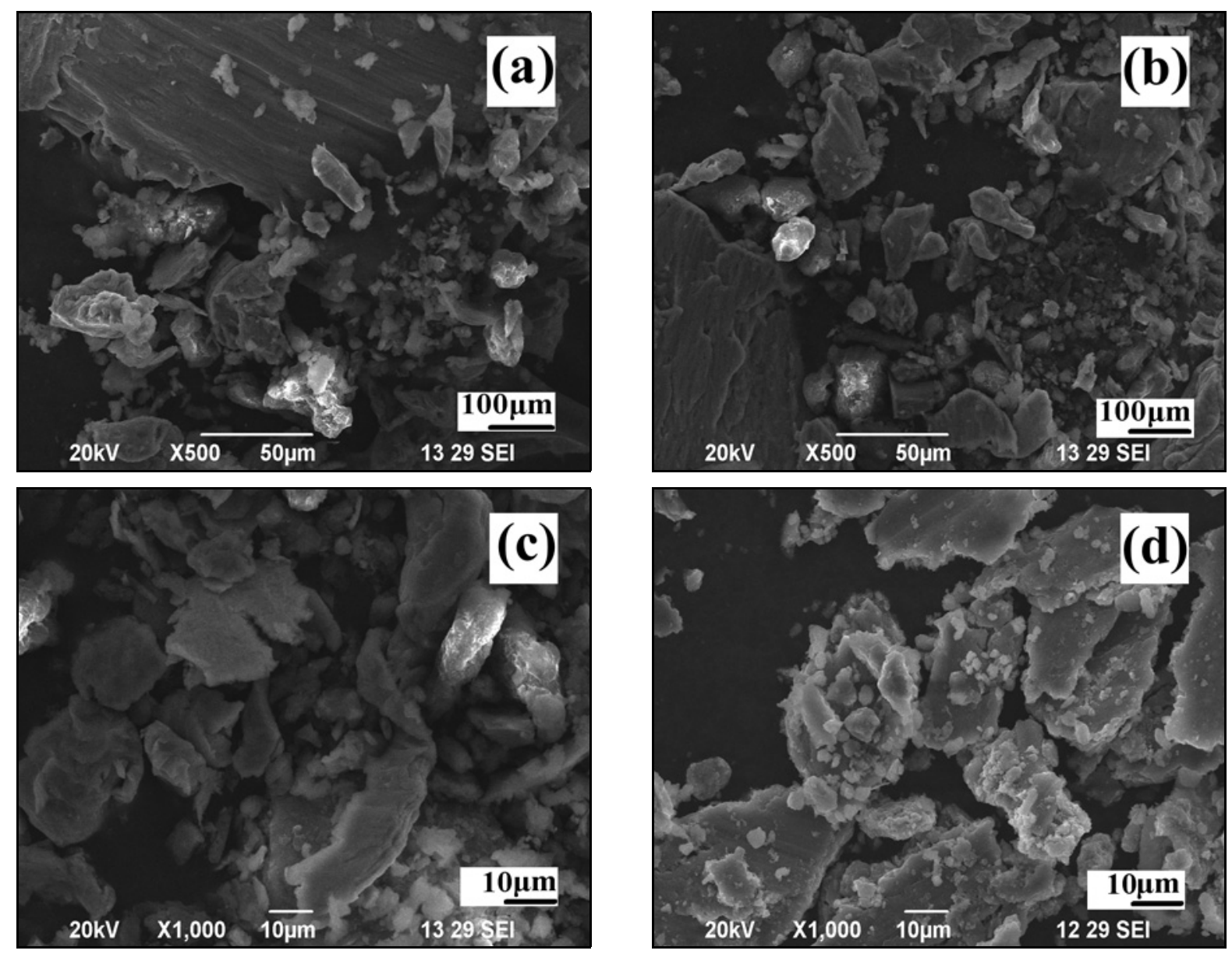

Fig. 8. SEM photomicrographs of wear debris of AA 6061 alloy reinforced with fly ash particles (a) 0 wt.\%; (b) 4 wt.\%; (c) 8 wt.\%; (d) 12 wt.\% tested under normal load of $24.9 \mathrm{~N}$.

the high contact stresses and increasing number of fine fly ash particles (due to the higher weight percentage of the fly ash particles). If we assume the average diameter of a fly ash particle to be $1.25 \mu \mathrm{m}$, then a normal load of $24.9 \mathrm{~N}$ develops a contact stress of approximately $1996 \mathrm{MPa}$, which is high enough to generate the fine wear debris.

The SEM microanalysis of the wear surface shows that for a fixed load $(24.9 \mathrm{~N})$ the amount of iron content on the wear surface increases with the increase of fly ash particulates in the composites. The SEM analysis of the wear debris also shows growth in the content of iron for a given normal load. The fly ash particles which trapped between the wear specimen and the counterface cause a microploughing effect on the contact surface of the square pin [26] suggested that a wear particle is detached due to tangential forces acting on surfaces causing nucleation of cracks at surface, which propagate in due course of time causing exposure of fresh surface followed by delamination. Surface delamination is also contributed to the process of debris formation.

The iron-rich layer tends to help in reducing the wear rate of the AMC by acting as a solid lubricant.
The beneficial effect of iron rich layers was reported by Alpas and Zhang [29]. The iron oxides present in fly ash are known to have a low coefficient of friction and thus are expected to provide an in situ solid lubrication effect. It can be told that fly ash particles not only protect the matrix by their high hardness but also by generating the fine iron-rich debris that act as an effective lubricating medium. It is widely believed that the coefficient of friction increases with the amount of hard reinforcement in the matrix. The mechanism, which generates the debris in fine scale during the sliding wear, appears to be analogous to the high-energy ball milling where repeated fracturing and welding leads to the generation of fine particles. The formation of the layered structure is characteristic of such a system. Figure 8a shows an example of the cracking of coarse debris and Fig. $8 \mathrm{~b}$ shows layered structure of a particle mostly rich in iron.

\section{Conclusion}

The dry sliding wear behaviour of AA6061/fly ash MMC is evaluated using a pin-on-disc apparatus. 

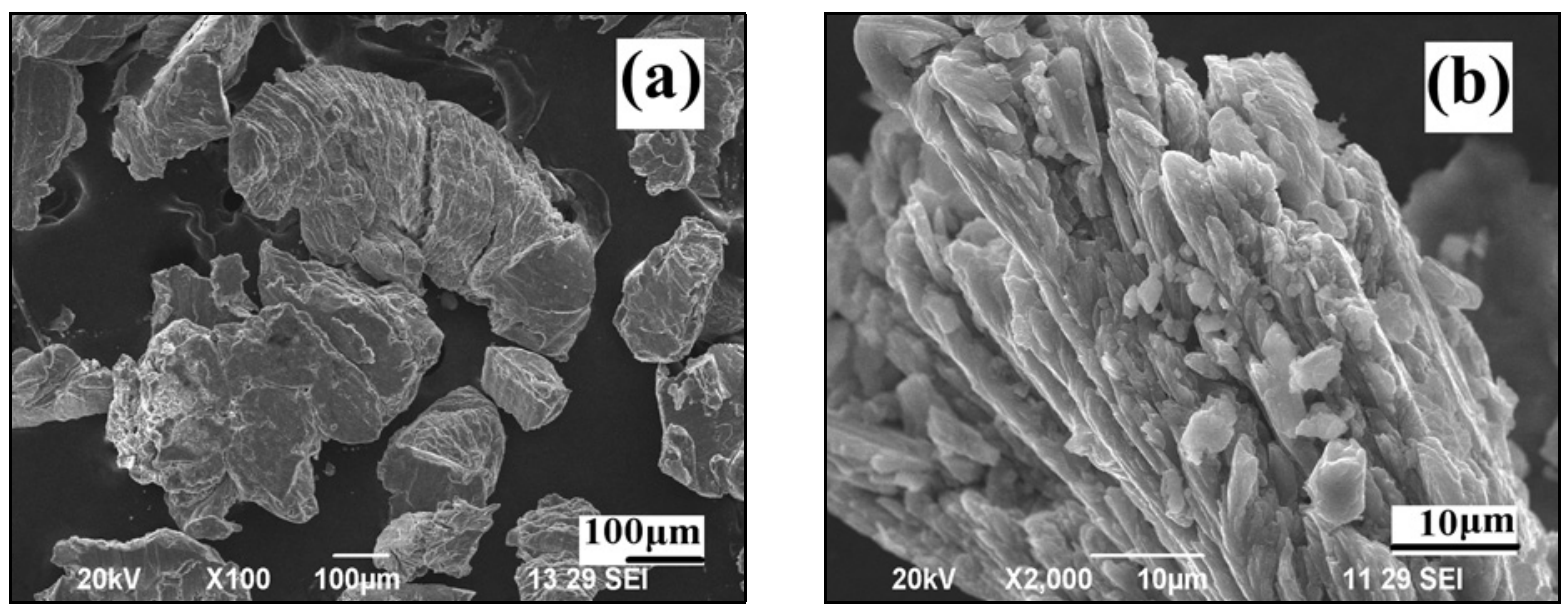

Fig. 9. (a) Cracking of a coarse debris and (b) formation of layered structure rich in iron in AA 6061-4 wt.\% fly ash MMC at $4.98 \mathrm{~N}$ load.

i. There is a definite increase in the wear resistance of AA6061 alloy by the addition of fly ash particles.

ii. The wear rate increases linearly with increasing normal load following Archard's law. AMCs have shown a lower rate of wear as compared to that observed in pure aluminium. This may be attributed to higher hardness of the composite due to the incorporation of hard fly ash particles. Wear rate also decreases linearly with increasing weight percentage of fly ash particles.

iii. The wear rate is proportional to wear parameters such as sliding velocity, sliding distance and normal load.

iv. The microstructural study of the specimen after wear test concludes that both adhesive and abrasive wear mechanisms contribute to wear of composites at lower load and denomination is more predominant at higher load.

v. The size of the debris also plays a vital role in deciding the wear behaviour of the alloy and the composites.

\section{References}

[1] Anoop, S., Natarajan, S., Babu, S. P. K.: Mater. Des., 30, 2009, p. 3831. doi:10.1016/j.matdes.2009.03.034

[2] León-Patińo, C. A., Drew, R. A. L.: Curr. Opin. Solid State Mater. Sci., 9, 2005, p. 211. doi:10.1016/j.cossms.2006.04.006

[3] Mondal, A. K., Kumar, S.: Wear, 267, 2009, p. 458. doi:10.1016/j.wear.2008.12.036

[4] Rao, R. N., Das, S.: Mater. Des., 32, 2011, p. 1066. doi:10.1016/j.matdes.2010.06.047

[5] Rodriguez, J., Poza, P., Garrido, M. A., Rico, A.: Wear, 262, 2007, p. 292.

[6] Kök, M., Özdin, K.: J. Mater. Process. Technol., 183, 2007, p. 301. doi:10.1016/j.jmatprotec.2006.10.021

[7] Chang, H., Binner, J., Higginson, R.: Wear, 268, 2010, p. 166. doi:10.1016/j.wear.2009.07.014
[8] Rohatgi, P. K., Kim, J. K., Gupta, N., Alaraj, S., Daoud, A.: Composites, Part A, 37, 2006, p. 430. doi:10.1016/j.compositesa.2005.05.047

[9] Rohatgi, P. K., Gupta, N., Alaraj, S.: J. Compos. Mater., 40, 2006, p. 1163. doi: $10.1177 / 0021998305057379$

[10] Hashim, J., Looney, L., Hashmi, M. S. J.: J. Mater. Process. Technol., 123, 2002, p. 251. doi:10.1016/S0924-0136(02)00098-5

[11] Sajjadi, S. A., Ezatpour, H. R., Parizi, M. T.: Mater. Des., 34, 2012, p. 106. doi:10.1016/j.matdes.2011.07.037

[12] Rajan, T. P. D., Pillai, R. M., Pai, B. C., Satyanarayana, K. G., Rohatgi, P. K.: Compos. Sci. Technol., 67, 2007, p. 3369. doi:10.1016/i.compscitech.2007.03.028

[13] Onat, A., Akbulut, H., Yilmaz, F.: J. Alloy Compd., 436, 2007, p. 375. doi:10.1016/i.jallcom.2006.07.057

[14] Ghomashchi, M. R., Vikhrov, A: J. Mater. Process. Technol., 101, 2000, p. 1. doi:10.1016/S0924-0136(99)00291-5

[15] Mondal, D. P., Goel, M. D., Das, S.: Mater. \& Des., 30, 2009, p. 1268. doi:10.1016/i.matdes.2008.06.059

[16] Rohatgi, P. K., Kim, J. K., Gupta, N., Alaraj, S., Daoud, A.: Composites Part A, 37, 2006, p. 430. doi:10.1016/j.compositesa.2005.05.047

[17] Blissett, R. S., Rowson, N. A.: Fuel, 97, 2012, p. 1. doi:10.1016/i.fuel.2012.03.024

[18] Ramachandra, M., Radhakrishna, K.: Wear, 262, 2007, p. 1450. doi:10.1016/i.wear.2007.01.026

[19] Patnaik, A., Satapathy, A., Chand, N., Barkoula, N. M., Biswas, S.: Wear, 268, 2010, p. 249. doi:10.1016/j.wear.2009.07.021

[20] Ramachandra, M., Radhakrishna, K.: J. Mater. Sci., 40, 2005, p. 5989. doi:10.1007/s10853-005-1303-6

[21] Kumar, P. R. S., Kumaran, S., Rao, T. S., Natarajan, S.: Mater. Sci. Eng. A, 527, 2010, p. 1501. doi:10.1016/j.msea.2009.10.016

[22] Mohanty, S., Chugh, Y. P.: Tribol. Int., 40, 2007, p. 1217. doi:10.1016/j.triboint.2007.01.005

[23] Hee, K. W., Filip, P.: Wear, 259, 2005, p. 1088. doi:10.1016/i.wear.2005.02.083

[24] Dadkar, N., Tomar, B. S., Satapathy, B. K.: Mater. 
Des., 30, 2009, p. 4369.

doi:10.1016/i.matdes.2009.04.007

[25] Kumar, S., Panwar, R. S., Pandey, O. P.: Ceram. Int. 39, 2013, p. 6333. doi:10.1016/i.ceramint.2013.01.059

[26] Suresha, B., Chandramohan, G., Jayaraju, T.: Polym. Compos., 29, 2008, p. 307. doi:10.1002/pc.20380
[27] Zhiqiang, S., Di, Z., Guobin, L.: Mat. Des., 26, 2005, p. 454. doi:10.1016/i.matdes.2004.07.026

[28] David Raja Selvam, J., Robinson Smart, D. S., Dinaharan, I.: Mater. Des., 49, 2013, p. 28. doi:10.1016/j.matdes.2013.01.053

[29] Alpas, A. T., Zhang, J.: Metall. Mater. Trans. A, 161, 1993, p. 273. doi:10.1007/BF02652272 